\title{
Capstone Design Projects in Engineering Curriculum: Present and Future
}

\author{
Adam Zielinski, Ph.D., P. Eng. \\ Department of Electrical and Computer \\ Engineering \\ University of Victoria \\ adam@uvic.ca
}

\author{
Kin Fun Li, Ph.D., P. Eng. \\ Department of Electrical and Computer \\ Engineering \\ University of Victoria \\ kinli@uvic.ca
}

\begin{abstract}
Students in the Department of Electrical and Computer Engineering at the University of Victoria enrolled in Computer, Electrical or Software Engineering programs are required to take a compulsory capstone Design Project course in their final year. The objective is to have engineering students go through the exercise of integrating their knowledge and skills acquired in earlier course work and co-op work terms in a design focused project to meet multiple criteria. The team members' work is evaluated based on their problem solving capability, project execution competence, oral and written communication skills, as illustrated in their progress and final reports, a public demonstration and competition of their project prototype, and a web site designed to promote their project. As the Design Project Coordinators for many years, the authors share many valuable observations. Short-term and long-term plans to improve the outcome-based learning experience of the students, and the organization, structure and execution of the course, will be described. The desirability of $a$ multidisciplinary approach and industrial cooperation, and the feasibility of international collaboration, will be discussed. Ways to encourage faculty to be actively involved in the Design Project course will be explored with respect to training of highly qualified personnel, promotion and tenure criteria, and potential for industrial consultancy. The role of co-op placements in the development of creative skills, teamwork and project management proficiency will be suggested.
\end{abstract}

\section{Introduction}

Virtually all of the accredited engineering programs in Canada contain a senior level course offering significant design experience (used to be called a capstone project). Canadian Engineering Accreditation Board (CEAB), Accreditation Criteria and Procedures, point 3.3.4.4 [1] states that:

The engineering curriculum must culminate in a significant design experience conducted under the professional responsibility of faculty licensed to practice engineering in Canada, preferably in the jurisdiction in which the institution is located. The significant design experience is based on the knowledge and skills acquired in earlier work and it preferably gives students an involvement in teamwork and project management.

In point 3.3.4.3, CEAB [1] defines design as:

Engineering design integrates mathematics, natural sciences, engineering sciences, and complementary studies in order to develop elements, systems, and processes to meet specific needs. It is a creative, iterative, and open-ended process, subject to constraints, which may be governed by standards or legislation to varying degrees depending upon the discipline. These constraints may also relate to economic, health, safety, and environmental, societal or other interdisciplinary factors.

The major Canadian research granting agency, National Science and Engineering Research Council Canada (NSERC), also recognizes the importance of early exposure to creative thinking amongst undergraduate students as stated in its policy [2]:

Training supported by NSERC ranges from undergraduate theses and summer projects to the postdoctoral level, and includes technical and other research personnel. The level and content of the training should be appropriate to the research field, with opportunities for interaction and collaboration with other researchers inside and outside the university, where appropriate. Undergraduate student participation in final-year projects and summer projects is an important first phase in research training and plays a major role in encouraging 
excellent students to pursue research careers.

It is a challenging task to combine the research (encouraged by NSERC) and design (required by $\mathrm{CEAB}$ ) aspects of undergraduate student involvement.

\section{Present Status}

Students in the Department of Electrical and Computer Engineering (ECE) at the University of Victoria (UVic) enrolled in one of the Computer, Electrical, or Software Engineering programs are required to take a one-term compulsory capstone Design Project course 499 in their final year (seventh term 4A or eighth term 4B). The objective of the course is to integrate knowledge and skills acquired in earlier course work in a design-focused project to meet multiple criteria. Teams of three to five students either choose a project from a pre-approved list of projects or propose their own projects that must be approved by the Design Project Coordinator (a registered professional engineer). Each team is supervised by at least one faculty member who is a professional engineer. The team members' work is evaluated based on their problem solving capability, project execution competence, oral and written communication skills, as illustrated in their progress and final reports, a public demonstration and competition of their project prototype, and a web site designed to promote their project. Detailed information on the Design Project course can be found in [3] that includes also archives of past projects. The interesting and prominent features of this course are:

- Students from Computer, Electrical, and Software Engineering programs are supposed to form an interdisciplinary project group. Furthermore, a group may even include students from other departments, in which case the group will have supervisors from the different departments.

- Students are encouraged to select topics proposed by external organizations or companies.

- Students are allowed to propose their own projects that must be approved by the course coordinator and group supervisor.

- Each group is expected to work on a different project in a term.

Past experience indicates that the majority of projects selected by students are proposed by the students themselves. The advantage of making their own proposal is the enthusiasm and dedication in carrying out the project. The disadvantage is a missed opportunity to develop meaningful links with local industry, other organizations and potential employers.
We are seeking proper ways to improve this situation but at the same time do not want to create a false expectation from the industry which might not realize that in addition to the Design Project course, students must take up to five other courses in the same term.

\section{Future Considerations}

\subsection{Students Input}

Unlike other courses being evaluated at each term, the Design Project course is not evaluated by the students or peers due to the multitude of supervisors involved. However such feedback is very important to monitor the quality of delivery and learning outcome. We are currently working on a scheme that can be smoothly integrated into existing university practice and procedures, and yet can capture the uniqueness of this course. The results of such evaluations will be made known to the department chair and can be used in the teaching evaluation of each individual faculty supervisor for tenure and promotion purposes.

\subsection{Students Progress}

In view of the recent $C E A B$ accreditation changes on the amount of engineering design activities to be supervised by professional engineers and the attributebased program outcomes assessment, there is an immediate need to have a monitoring tool in place for the Design Project course. A pilot project has been initiated in the Summer of 2010 to monitor the activities of each project design team. Based on an existing tool developed by the InSPiRe research group at UVic [7], a web-based progress reporting tool has been implemented and made available to the supervisor (one of the authors) of a design project team. Group members are required to enter their individual activities weekly. Each member's entry must be validated by all other group members as shown in Figure 1. This form of peer monitoring naturally reflects the actual contribution of each group member. The supervisor of a group is also required to validate the team's entry at various milestones throughout the term. As shown in Figure 2, the supervisor can view the progress of the group in terms of hours and percentage spent on project activities by each group member. Using this tool, a supervisor has a means to assess the work done by the group as well as by the individual group members, thus making it possible to assign different grades to each member since currently all members of a group receive the same grade. In addition, the project activity log is a useful documentation in a CEAB accreditation assessment process. 


\subsection{Co-op Placements}

The Bachelor of Engineering programs in the Faculty of Engineering at UVic have a compulsory coop component that requires a minimum of four work terms (each 13 weeks of duration) at suitable jobs in industry or other organizations [4]. After each work term, students are required to submit a work term report that is evaluated by faculty or co-op coordinators. It is suggested that the work term experience be used to identify real-life problems that can be addressed and possibly solved by groups of students during their Design Project course. This will provide an exciting opportunity for students and faculties to address real-world problems. The existing final-year course ENGR 466 Technical Report [5], that requires students to demonstrate written communication and analytical skills, may be used to document such involvements.

\subsection{Undergraduate Thesis}

To increase the weight and depth of student involvement in research and design, an undergraduate thesis may be introduced. This has already been implemented in some Canadian universities. Possible implementation of this idea in the ECE Department will involve two academic terms:

- The first term is dedicated to problem identification and the associated research, to be documented in the ENGR 466 Technical Report.

- The second term is dedicated to the design and implementation of the selected problem, to be documented in the 499 Design Project Course.

\subsection{International Collaboration}

Availability of Internet access as a convenient way for distant communication and interaction, including voice and video, enables us to add new dimension and excitement to project based courses. The authors presently are working on international collaboration with universities in the Philippines and China. The following are the perceived advantages of such collaboration:

- Co-op placements may be created for participating students.

- Undergraduate and graduate students alike may be recruited by the universities within the framework of a formal exchange agreement.
- Students working on common projects could communicate, collaborate and compete over the Internet (via documents, voice, and video).

- Suitable arrangements can be made to record lectures or seminars to be viewed as streamed videos at any convenient time. This service may also benefit home institution students who have missed a class.

Implementation of some of the above ideas is planned to take place in the Spring 2011 offering of the Design Project course. The long-term objective of the proposal is to establish grounds for possible evaluation by CEAB of the Computer, Electrical and Software Engineering programs at other overseas universities. A positive evaluation will provide opportunities for these students in other countries, since their engineering programs could be recommended by CEAB as "substantive equivalent” to accredited programs in Canada. Such evaluations have already been done in Costa Rica (8 programs), Peru (3 programs), Austria (2 programs), and Russia (1 program) [1].

\section{References}

[1] Canadian Engineering Accreditation Board, Accreditation Criteria and Procedures, 2009. Available: http://www.engineerscanada.ca/e/pu_ab.cfm [May 17, 2010] [2] NSERC Policy and Guidelines on the Assessment of Contributions to Research and Training, Contributions to the Training of Highly Qualified Personnel, 2009. Available: http://www.nserc-crsng.gc.ca/NSERC-CRSNG/PoliciesPolitiques/assesscontrib-evalcontrib_eng.asp [May 17, 2010] [3] CENG/ELEC/SENG 499 - Design Project, Summer 2010. Available: http://www.ece.uvic.ca/499/ [May 17, 2010]

[4] Co-operative education: Available:

http://www.uvic.ca/engineering/undergrad/coop/index.php

[May 17, 2010]

[5] ENGR 446: Technical Report. University of Victoria Calendar, 2009-2010. Available:

http://web.uvic.ca/calendar2009/CDs/ENGR/446.html [May 17, 2010]

[6] Undergraduate thesis: University of Toronto, 2008. Availavle:

http://www.chem-eng.utoronto.ca/undergrad/undergrads/ugthesis.htm [May 17, 2010]

[7] Information Security and Privacy Research Group InSPiRe, University of Victoria. 


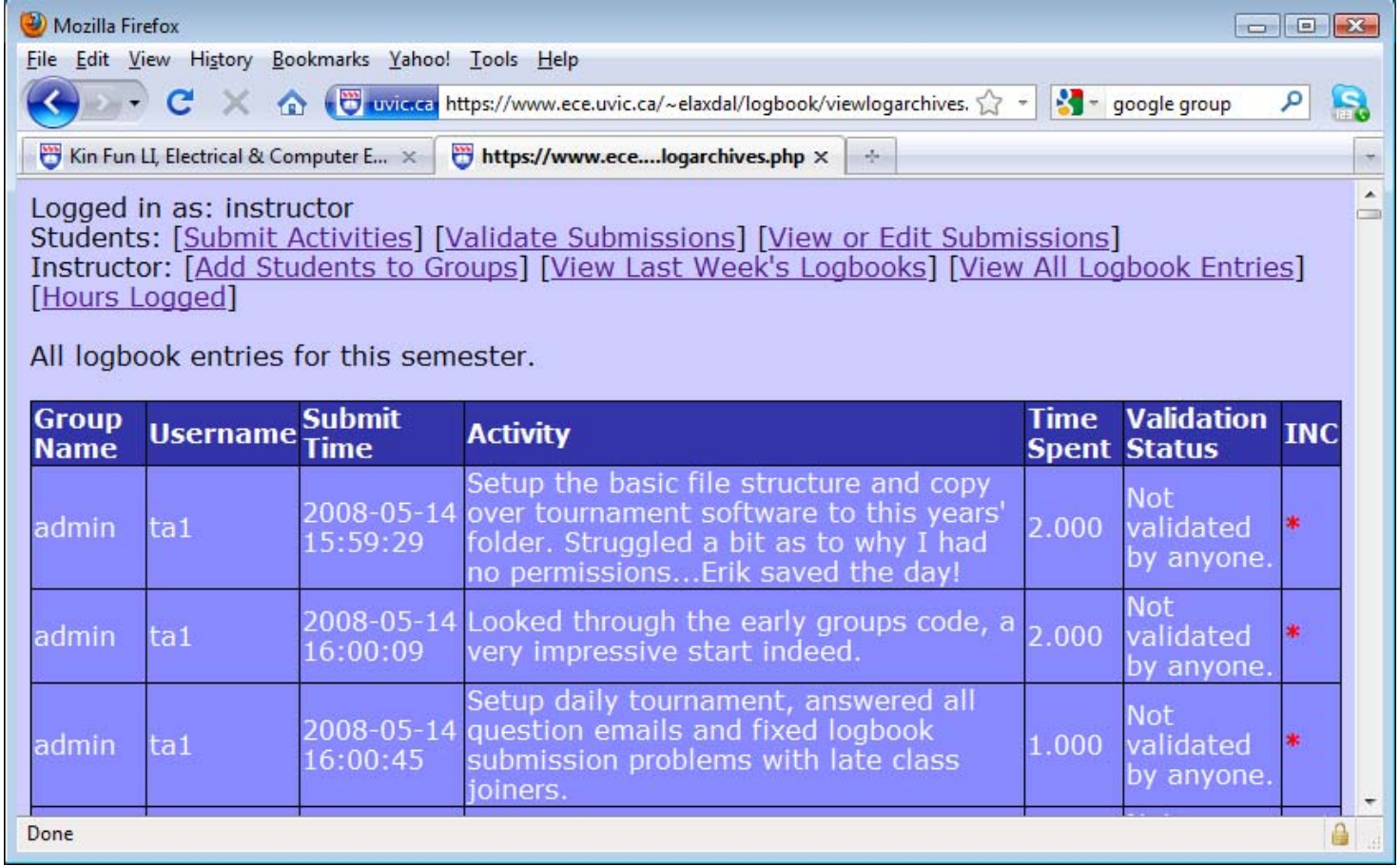

Figure 1. Individual activity and validation.

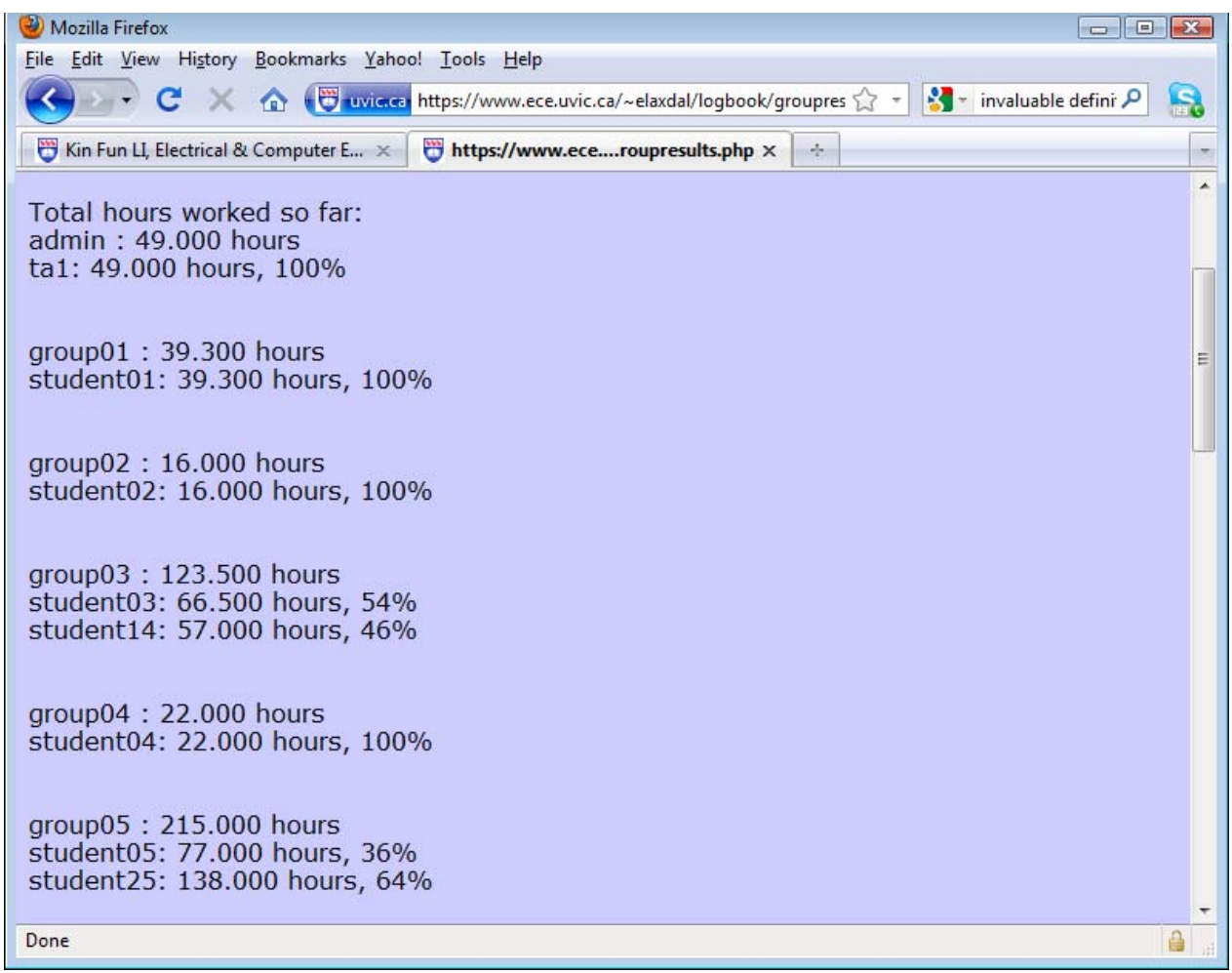

Figure 2. Progress tracking and individual contribution. 